Koster, E.S., Meeteren, M.M. van, Dijk, M. van, Bemt, B.J.F. van de, Ensing, H.T., Bouvy, M., Blom, L., Dijk, L. van. Patient-provider interaction during medication encounters: a study in outpatient pharmacies in the Netherlands. Patient Education and Counseling: 2015, 98(7),843- 7 848

\begin{tabular}{|l|l|}
$\begin{array}{l}\text { Postprint } \\
\text { Version }\end{array}$ & 1.0 \\
\hline Journal website & http://www.pec-journal.com/article/S0738-3991(15)00098-1/abstract \\
\hline Pubmed link & $\underline{\text { http://www.ncbi.nlm.nih.gov/pubmed/25825256 }}$ \\
\hline DOI & $10.1016 /$ j.pec.2015.03.007
\end{tabular}

This is a NIVEL certified Post Print, more info at http://www.nivel.eu

\title{
Patient-provider interaction during medication encounters: A study in outpatient pharmacies in the Netherlands
}

\author{
ELLen S. KOSTER ${ }^{A,}$, MARIJKe M. VAN MEETEREN ${ }^{\mathrm{A}}$, MARLOES VAN DIJK ${ }^{\mathrm{B}}$, BART J.F. VAN \\ DE BEMT ${ }^{\mathrm{C}, \mathrm{D}}$, HENDRIKUS T. ENSING ${ }^{\mathrm{A}, \mathrm{E}, \mathrm{F}}$, MARCEL L. BOUVY ${ }^{\mathrm{A}}$, LYDA BLOM ${ }^{\mathrm{A}}$, LISET VAN \\ DIJK $^{\mathrm{B}}$ \\ ${ }^{a}$ Division of Pharmacoepidemiology and Clinical Pharmacology, Utrecht University, Utrecht, \\ The Netherlands \\ ${ }^{\mathrm{b}}$ Netherlands Institute of Health Services Research (NIVEL), Utrecht, The Netherlands \\ ${ }^{\mathrm{C}}$ Department of Pharmacy, Sint Maartenskliniek, Nijmegen, The Netherlands \\ ${ }^{\mathrm{d}}$ Department of Pharmacy, Radboud University Medical Center, Nijmegen, The Netherlands \\ e Utrecht University of Applied Sciences, Research Group Process Innovations in \\ Pharmaceutical Care, Hogeschool Utrecht, Utrecht, The Netherlands ${ }^{\dagger}$ Zorggroep Almere, \\ Outpatient Pharmacy "de Brug 24/7", Flevoziekenhuis, The Netherlands
}

\begin{abstract}
Objective: To describe communication between pharmacy staff and patients at the counter in outpatient pharmacies. Both content and communication style were investigated.

Methods: Pharmaceutical encounters in three outpatient pharmacies in the Netherlands were video-recorded. Videos were analyzed based on an observation protocol for the following information: content of encounter, initiator of a theme and pharmacy staff's communication style.

Results: In total, 119 encounters were recorded which concerned 42 first prescriptions, 16 first refill prescriptions and 61 follow-up refill prescriptions. During all encounters, discussion was mostly initiated by pharmacy staff (85\%). In first prescription encounters topics most frequently discussed included instructions for use (83\%) and dosage instructions (95\%). In first refill encounters, patient experiences such as adverse effects (44\%) and beneficial effects (38\%) were regularly discussed in contrast to follow-up refills (7\% and 5\%). Patients' opinion on medication was hardly discussed.

Conclusion: Pharmacy staff in outpatient pharmacies generally provide practical information, less frequently they discuss patients' experiences and seldom discuss patients' perceptions and preferences about prescribed medication.

Practice implications: This study shows there is room for improvement, as communication is still not according to professional guidelines. To implement
\end{abstract}


Koster, E.S., Meeteren, M.M. van, Dijk, M. van, Bemt, B.J.F. van de, Ensing, H.T., Bouvy, M., Blom, L., Dijk, L. van. Patient-provider interaction during medication encounters: a study in outpatient pharmacies in the Netherlands. Patient Education and Counseling: $2015,98(7), 843-7$ 848

professional guidelines successfully, it is necessary to identify underlying reasons for not following the guidelines.

\section{INTRODUCTION}

Medication counselling is an essential part of pharmaceutical care [1], especially in first dispensing and first refills. At the pharmacy counter pharmacy staff has ample opportunity to inform patients about their medication and support them in using their medication properly [2], [3] and [4]. Effective communication between providers and patients about medication use is associated with patients' satisfaction, recall of information and eventually their health status [4], [5], [6] and [7]. Research shows that patients who are sufficiently informed about the risks and benefits of their treatment, show higher adherence to their prescribed medical treatment [6], [7], [8], [9], [10], [11] and [12]. For communication to be effective, both the healthcare provider and the patient should actively engage in these medical encounters. Healthcare providers should counsel patients to enable informed decisions and inform patients how to proper use the medication. Patients should express perceived side effects and their beliefs and concerns. This results in an effective and efficient patient-centered encounter in which a patient perceives support and care [13], [14] and [15].

The Royal Dutch Pharmacists Association has issued guidelines on pharmaceutical care, amongst which guidelines about the different kinds of prescription drug dispensing contacts (available from www.knmp.nl, consulted November 27th 2014). In case of dispensing a new prescribed drug, pharmacy staff - including pharmacy technicians and pharmacists - have to explain patients what they may expect from the prescribed drug. Information is to be given about the drug activity, side-effects, possible interactions with other drugs and drug instructions. In case of delivering a first refill prescription, pharmacy staff above all ask patients about their drug experiences. In addition, they provide the same information as given in case of a new prescribed drug. In case of follow-up refills, pharmacy staff ask patients about their drug experiences and be attentive for any new questions, whereas they also pay attention to drug adherence.

Traditionally, pharmacies in the Netherlands were divided into hospital and community pharmacies. In 2001, a new connection between these two types of pharmacies was introduced because of the need for good pharmaceutical care for patients discharged from the hospital: the outpatient pharmacy [16] and [17]. Outpatient pharmacies are located in a hospital or clinic and dispense medication to patients discharged from the hospital and patients in outpatient therapy. In 2012, about two third of all Dutch hospitals had an outpatient pharmacy [17] and [18]. The outpatient pharmacy was expected to improve quality of care because of collaboration of pharmacy staff with medical specialists in the hospital as well as with general practitioners in the primary care setting. In outpatient pharmacies, the majority of prescriptions concern first dispenses in contrast to the dispenses in the community pharmacy, therefore medication counseling during (first) prescription encounters in outpatient pharmacies might be better or different [17]. 
Koster, E.S., Meeteren, M.M. van, Dijk, M. van, Bemt, B.J.F. van de, Ensing, H.T., Bouvy, M., Blom, L., Dijk, L. van. Patient-provider interaction during medication encounters: a study in outpatient pharmacies in the Netherlands. Patient Education and Counseling: $2015,98(7), 843-7$ 848

However, there is limited research on patient-provider communication in outpatient pharmacies and whether it is in line with guidelines. The aim of this study was to describe both the content and the communication style during encounters between pharmacy staff and patients about prescribed medication in outpatient pharmacies.

\section{METHODS}

\subsection{Design and setting}

We conducted an observational study in three outpatient pharmacies in the Netherlands. The study protocol was approved by the UPPER (Utrecht Pharmacy Practice Research network for Education and Research) Institutional Review Board of the division of Pharmacoepidemiology and Clinical Pharmacology, Utrecht University. Four outpatient pharmacies were invited to participate in the study, three agreed to participate. These pharmacies were specifically approached based on their interest in (research) projects about patient care. One of the pharmacies was located in a university hospital, one in a general hospital and one in a clinic that specializes in posture and movement.

\subsection{Study population}

Discharged patients and ambulatory patients visiting a hospital clinic aged 18 years or older who visited the outpatient pharmacy to pick up a prescription were asked to participate in the study. Both, patients filling medication for themselves and persons filling prescriptions for others were invited to participate. Both new prescriptions and refills were included. The aim of the study was verbally explained to the patients after which they could decide whether or not to participate. All participants signed informed consent. Patients were excluded if they: (1) visited the pharmacy for medical advice only, (2) collected Over-The-Counter medicines only, (3) did not receive their medication during the encounter or (4) had insufficient comprehension of Dutch language.

\subsection{Data collection}

Pharmaceutical encounters between patients and pharmacy staff - mostly pharmacy technicans - were recorded on video. Previous studies have shown that video recordings are a good way to assess healthcare providers communications skills [19] and [20]. The camera was positioned at the patients' back, therefore only pharmacy staff members were identifiable from the front whereas the patient was not. After the encounter, socio-demographic information was collected from the patient and the pharmacy staff member noted the names of the medication and the type of prescription.

The encounters were divided into first, first refill and follow-up refill prescription encounters. An encounter was classified as first prescription encounter when patients received at least one medicine for the first time. First refill prescription encounters were defined as encounters in which patients received at least one medicine for the 
Koster, E.S., Meeteren, M.M. van, Dijk, M. van, Bemt, B.J.F. van de, Ensing, H.T., Bouvy, M., Blom, L., Dijk, L. van. Patient-provider interaction during medication encounters: a study in outpatient pharmacies in the Netherlands. Patient Education and Counseling: $2015,98(7), 843-7$ 848

second time. When just follow-up refill prescription medication was provided to patients, it was called follow-up refill prescription encounter.

\subsection{Data analysis}

The videotapes were analyzed using an observation protocol for the following information: (1) content of the encounter (2) initiator of a communication theme or subject (patient or pharmacy staff) and (3) communication style of the pharmacy staff. Regarding the content of the encounter, the observation protocol included the MEDICODE, a checklist consisting of four topics focusing on the description of medical encounters related to medicines [21] and [22]. An extra element was added to assess who initiated the topic (the patient or the pharmacy staff member). To characterize the communication style of the pharmacy staff, the observation protocol included items based on a study by Linn et al. and the Consumer Quality-Index (CQI) Pharmaceutical Care [23] and [24]. These items were scored on a four-point Likert scale by the observers. The observation protocol was pre-tested with (simulated) student-patient interactions at the Utrecht School of Pharmacy.

Two observers (MvM and MvD) watched five video recordings to reach agreement on how to interpret the observation protocol. Inter-rater reliability, expressed as Cohen's Kappa was 0.80 . The other recordings were observed by one observer $(\mathrm{MvM})$. To examine differences in discussed MEDICODE themes between first, first refill and refill prescriptions, ANOVA testing was used. $p$ Values $<0.05$ were considered statistically significant. Data were analysed with STATA version 13.0 (StataCorp, Texas, USA).

\section{RESULTS}

\subsection{Participants}

A total of 145 patients were invited to participate in the study, of which 17 patients refused (88.3\% response). Of the 128 patients willing to participate, 9 patients were excluded because they did not receive their medication during the encounter or only visited the pharmacy for medical advice, resulting in a total of 119 included patients. Of these 119 patients, 28 visited the pharmacy for filling medicines for someone else. The characteristics of the study population are shown in Table 1. Approximately one third of the encounters concerned first prescriptions. The mean duration of the observed encounters was $8.5 \mathrm{~min}$ : the shortest encounter was $1.3 \mathrm{~min}$ and the longest took $38.3 \mathrm{~min}$.

\section{[TABLE 1]}

\subsection{Content and initiative during prescription encounters}

In most cases (85\%), a pharmacy staff member initiated the discussion. In about one fifth of the encounters pharmacy staff asked patients if they had questions (19\%) and in a quarter (25\%) of the encounters the patient asked the pharmacy technician questions about the medication. Overall, the most discussed themes were dosage information (69\%), name of the medication (65\%) and the administration form of the 
Koster, E.S., Meeteren, M.M. van, Dijk, M. van, Bemt, B.J.F. van de, Ensing, H.T., Bouvy, M., Blom, L., Dijk, L. van. Patient-provider interaction during medication encounters: a study in outpatient pharmacies in the Netherlands. Patient Education and Counseling: $2015,98(7), 843-7$ 848

medication (55\%). Pharmacy staff rarely asked patients about their opinion (1\%), concerns (8\%), doubts (3\%) and objections (1\%) regarding medication. When discussed this was generally on the patient's initiative. Only once the pharmacy technician initiated a discussion on patient's preferences and perceptions. Neither patients nor pharmacy staff addressed themes such as adherence.

Table 2a, Table 2b and Table 2c show the themes discussed in the three types of encounters (new prescriptions, first refills and repeat refills). The average number of discussed themes was significantly higher during first prescription encounters compared to repeat prescription encounters (7.7 vs. 4.0 themes, respectively, $p<0.05$ ). No significant differences in the number of discussed themes were observed between first prescriptions and first refill prescriptions.

\section{[TABLE 2A] [TABLE 2B] [TABLE 2C]}

\subsubsection{First prescription encounters}

General drug information was given in the majority of the 42 observed first prescription encounters, e.g. dosage information (95\%), issues about how to use the medicine (83\%) and form of the medication (74\%), the mechanism of action of the drug (60\%) and possible adverse effects (52\%). When collecting first prescriptions, patients asked questions in $11 \%$ of the cases (Table 2a). Mechanism of action, possible adverse effects, medication-usage issues were significantly $(p<0.01)$ more discussed in first prescription encounters compared to first refill and refill prescription encounters.

\subsubsection{First refill prescription encounters}

In the 16 observed first refill prescription encounters topics related to medication changes, such as adjustment of the dosage (75\%) were discussed most frequently. Adverse effects and beneficial effects were discussed in 44\% and 38\% of the encounters. In almost a quarter (22\%) of the encounters in which experiences regarding medication were discussed, patients took initiative (Table 2b). In first refill prescription encounters, beneficial effects and adverse effects were significantly more discussed than in follow-up refill prescription encounters $(p<0.001)$.

\subsubsection{Follow-up refill prescription encounters}

For the 61 observed follow-up refill prescriptions mostly general drug information was given (Table 2c). Adverse effects and beneficial effects were rarely discussed. In the encounters in which experiences with regard to medication (20\%) were discussed, the discussion was most of the time started by the patient (58\%).

\subsection{Communication style}

Table 3 shows elements scored related to the communication style of the pharmacy staff members. Pharmacy staff scored relatively high (mostly between 3.8 and 4.0) on elements of communication style such as speaking calmly. They only scored 
Koster, E.S., Meeteren, M.M. van, Dijk, M. van, Bemt, B.J.F. van de, Ensing, H.T., Bouvy, M., Blom, L., Dijk, L. van. Patient-provider interaction during medication encounters: a study in outpatient pharmacies in the Netherlands. Patient Education and Counseling: $2015,98(7), 843-7$ 848

\section{niv}

lower on making eye contact. In 18 encounters (15\%) an emotional cue from the patient about medication use was observed. Response of pharmacy staff varied: in one encounter (6\%) the pharmacy technician neglected the cue, in eight cases (44\%) there was a minimal reaction, in five encounters (28\%) the pharmacy technician acknowledged the cue and in four (22\%) cases the cue was explored. Pharmacy staff sometimes stimulated the patients to ask questions; in eight encounters (7\%) pharmacy staff assessed understanding of patients about their medication and in seven encounters (6\%) pharmacy staff stimulated patients' questions at the end of the consultation. Furthermore, we assessed whether the patients' opinion about medication used was discussed during the encounter. In 17 encounters (14\%) patients' opinion was discussed. In most cases the discussion was about practical problems (77\%), such as whether the patient was able to open the package (Table 4).

\section{[TABLE 3] [TABLE 4]}

\section{DISCUSSION AND CONCLUSION}

\subsection{Discussion}

This observational study investigated patient-provider interaction about prescription medication at the counter in outpatient pharmacies. Differences were observed between the different types of encounters. During first prescription encounters pharmacy staff mostly led the encounter and gave practical information. During the first refill patients are asked about their experiences in approximately $50 \%$ of the cases, but pharmacy staff does not explore further to discover underlying reasons for possible problems. During refill prescriptions encounters patients' experiences are rarely discussed. Furthermore, pharmacy staff does not encourage patients verbally to actively participate in the encounter, whilst previous research has shown that patients' perceptions toward their relationships (e.g. trust and involvement in decisions) with care providers are important drivers of good medication use and adherence [25] and [26].

Furthermore, research carried out in the community pharmacy setting with patients filling a first prescription for chronic medication showed that pharmacy technicians dominate the conversation and ask few questions to the patient [15]. This is in line with the results of our study in which pharmacy staff asks few questions to explore reasons for possible problems in a patient's medication use regimen. Furthermore, van Hulten et al. [15] showed that during these consultations, mostly, information was given without really exploring the needs of the patient. A systematic review performed by Stevenson and co-workers [14] on communication about medicines between patients and healthcare providers showed that patients are more passive during consultations and healthcare providers dominate the consultation. Furthermore, questions related to patient preferences and adherence were only asked in a minority of the consultations. 
Koster, E.S., Meeteren, M.M. van, Dijk, M. van, Bemt, B.J.F. van de, Ensing, H.T., Bouvy, M., Blom, L., Dijk, L. van. Patient-provider interaction during medication encounters: a study in outpatient pharmacies in the Netherlands. Patient Education and Counseling: $2015,98(7), 843-7$ 848

\subsection{Strengths and limitations}

To our knowledge this is the first study about patient-provider interaction conducted in the outpatient pharmacy setting. There has been research in the community pharmacy setting. However, most studies did not involve video-recordings and are therefore often focused on a one-way communication of pharmacy staff members to patients [27]. By using video-recordings we were able to look both at content of and style of communication in outpatient pharmacies and to study the interaction between patients and pharmacy staff members. Since the introduction of outpatient pharmacies in 2001, approximately two third of the hospitals in the Netherlands house an outpatient pharmacy. There has never been done research yet on the quality of care in these fast growing new type of pharmacies. Noordman et al. [28] recently showed video recordings can be used in feedback to improve communication skills of healthcare providers. So, this study offers the participating pharmacies possibilities to improve their patient-provider interaction. A potential limitation of this study might be that data were collected in three different outpatient pharmacies in different settings, with relatively small numbers of observations per pharmacy site, which hampers solid conclusions about differences by site. Differences between pharmacies might have been caused by differences in expertise of the pharmacy staff members or in the pharmacy or hospital setting.

There might be some degree of selection as participating pharmacies might be more interested and more engaged in patient counseling. Therefore, the results presented in this study could even be an overestimation of the real-life situation. Furthermore, the communication style may have been influenced by the presence of a camera. Pharmacy staff may have been more aware of their way of communicating during the measurement days which could have led to more positive outcomes.

\subsection{Practice implications}

It is important to address patient provider interaction in the pharmacy as previous research has shown associations between communication and medication outcomes. Linn et al. [23] and [29] showed the importance of tailored communication to improve adherence and Yin et al. [30] showed a reduction in medication errors by using patient centered counselling and advanced communication techniques.

Communication in outpatient pharmacies does not fully match professional guidelines (available from: www.knmp.nl). These guidelines support the pharmacy staff to assist the patients in their medication use at the counter. During a first prescription encounter, pharmacy staff has to explain the patient how to use the medication, the mechanism of action of the drug and the possible adverse effects of the drug. The pharmacy staff member, most often a technician, has to check whether the patient has understood that information. During refill prescription encounters, pharmacy staff has to ask patients about their experiences with their medication use and if necessary, pharmacy staff has to initiate a discussion about over- and underuse. In all types of encounters, pharmacy staff is supposed to check whether the patient has any remaining questions. The outpatient pharmacies in our study comply with the guidelines about informing patients about how to use their medication, 
Koster, E.S., Meeteren, M.M. van, Dijk, M. van, Bemt, B.J.F. van de, Ensing, H.T., Bouvy, M., Blom, L., Dijk, L. van. Patient-provider interaction during medication encounters: a study in outpatient pharmacies in the Netherlands. Patient Education and Counseling: 2015, 98(7),843848

especially in new prescription contacts. However, the pharmacies did not comply with the guidelines about asking patients about their drug use experiences and adherence in the refill contacts. In many encounters patients are asked about their experiences. However in the case of problems with the medication regimen, pharmacy staff members often to not explore underlying reasons for these problems. As patients do not have an active role during the encounters their drug use problems may remain undiscovered. More research is needed to find out why pharmacy staff member communicate the way they do. Further research should focus on the question whether or not pharmacy staff is aware of the guidelines and their reasons for not adhering to these guidelines. During education of pharmacy staff, especially of pharmacy technicians who most of the time perform pharmacy encounters when patients (re)fill their medication, more attention could be given to content and implementation of these guidelines.

\subsection{Conclusion}

Pharmacy staff members in outpatient pharmacies generally provide practical drug information, less frequently they discuss patients' experiences with the medication and they seldom discuss patient perceptions and preferences. Communication is not fully according to professional guidelines, especially patient-centeredness could be improved.

\section{REFERENCES}

[1] J.W. van Mil. Pharmaceutical care in community pharmacy: practice and research in the Netherlands. Ann Pharmacother, 39 (2005), pp. 1720-1725

[2] A.M. Alkhawajah, A.E. Eferakeya. The role of pharmacists in patients' education on medication. Public Health, 106 (1992), pp. 231-237

[3] L. Blom, M. Wolters, M. Ten Hoor-Suykerbuyk, J. van Paassen, A. van Oyen. Pharmaceutical education in patient counseling: $20 \mathrm{~h}$ spread over 6 years? Patient Educ Couns, 83 (2011), pp. 465-471

http://dx.doi.org.proxy.library.uu.nl/10.1016/j.pec.2011.05.018

[4] F. Ax, J.O. Branstad, T. Westerlund. Pharmacy counselling models: a means to improve drug use. J Clin Pharm Ther, 35 (2010), pp. 439-451

[5] L.C. Zandbelt, E.M. Smets, F.J. Oort, M.H. Godfried, H.C. de Haes. Medical specialists' patient-centered communication and patient-reported outcomes. Med Care, 45 (2007), pp. 330-339

[6] S.B. Calvert, J.M. Kramer, K.J. Anstrom, L.A. Kaltenbach, J.A. Stafford, N.M. Allen LaPointe. Patient-focused intervention to improve long-term adherence to evidence-based medications: a randomized trial. Am Heart J, 163 (2012), pp. 657-665 (e1)

[7] K.B. Zolnierek, M.R. Dimatteo. Physician communication and patient adherence to treatment: a meta-analysis. Med Care, 47 (2009), pp. 826-834

[8] E.B. Anderson. Patient-centeredness. A new approach. Nephrol News Issues, 16 (2002), pp. 80-82

[9] L.N. Ngoh. Health literacy: a barrier to pharmacist-patient communication and medication adherence. J Am Pharm Assoc, 49 (2009), pp. e132-e146 (quiz e147-9)

[10] L. Osterberg, T. Blaschke. Adherence to medication. N Engl J Med, 353 (2005), pp. 487-497

[11] L.M. Ong, J.C. de Haes, A.M. Hoos, F.B. Lammes. Doctor-patient communication: a review of the literature. Soc Sci Med, 40 (1995), pp. 903-918

[12] J.H. Robinson, L.C. Callister, J.A. Berry, K.A. Dearing. Patient-centered care and adherence: definitions and applications to improve outcomes. J Am Acad Nurse Pract, 20 (2008), pp. 600-607 
Koster, E.S., Meeteren, M.M. van, Dijk, M. van, Bemt, B.J.F. van de, Ensing, H.T., Bouvy, M., Blom, L., Dijk, L. van. Patient-provider interaction during medication encounters: a study in outpatient pharmacies in the Netherlands. Patient Education and Counseling: 2015, 98(7),843848

[13] S. van Dulmen. The value of tailored communication for person-centred outcomes J Eval Clin Pract, 17 (2011), pp. 381-383

[14]. F.A. Stevenson, K. Cox, N. Britten, Y. Dundar. A systematic review of the research on communication between patients and health care professionals about medicines: the consequences for concordance. Health Expect, 7 (2004), pp. 235-245

[15] R. van Hulten, L. Blom, J. Mattheusens, M. Wolters, M. Bouvy. Communication with patients who are dispensed a first prescription of chronic medication in the community pharmacy. Patient Educ Couns, 83 (2011), pp. 417-422

[16]. T. Visser, J.G. Van Dam. Transurale farmacie staat voor kwaliteit. Het ziekenhuis, 33 (1996), pp. 10-12

[17] Stichting Farmaceutische Kengetallen. Meer eerste uitgiftes in poliklinische apotheek [More first dispenses in outpatient pharmacies] Pharm Weekbl, 145 (2010), p. 11

[18] E. Bos. Apotheker: Van solist naar teamspeler. Pharm Weekbl, 147 (2012), pp. 10-13

[19] T.C. Olde Hartman, E. van Rijswijk, S. van Dulmen, E. van Weel-Baumgarten, P.L. Lucassen, C. van Weel. How patients and family physicians communicate about persistent medically unexplained symptoms. A qualitative study of video-recorded consultations. Patient Educ Couns, 90 (2013), pp. 354-360

[20] J.M. Bensing, F. Tromp, S. van Dulmen, A. van den Brink-Muinen, W. Verheul, F.G. Schellevis. Shifts in doctor-patient communication between 1986 and 2002: a study of videotaped general practice consultations with hypertension patients. BMC Fam Pract, 7 (2006), p. 62

[21] C. Richard, M.T. Lussier. MEDICODE. An instrument to describe and evaluate exchanges on medications that occur during medical encounters. Patient Educ Couns, 64 (2006), pp. 197-206

[22] C. Richard, M.T. Lussier. Nature and frequency of exchanges on medications during primary care encounters. Patient Educ Couns, 64 (2006), pp. 207-216

[23] A.J. Linn, J.C. van Weert, B.C. Schouten, E.G. Smit, A.A. van Bodegraven, L. van Dijk. Words that make pills easier to swallow: a communication typology to address practical and perceptual barriers to medication intake behavior. Patient Prefer Adherence, 6 (2012), pp. 871-885

[24] M. Vervloet, C.P. Linschoten, L. van Dijk. CQ-index farmaceutische zorg kwaliteit vanuit het perspectief van patiënten: Meetinstrumentontwikkeling, 9789069058719 (2007)

[25] A.M. Bauer, M.M. Parker, D. Schillinger, et al. Associations between antidepressant adherence and shared decision-making, patient-provider trust, and communication among adults with diabetes: diabetes study of northern California (DISTANCE) J Gen Intern Med, 29 (2014), pp. 1139-1147

[26] Y. Liu, J.L. Malin, A.L. Diamant, A. Thind, R.C. Maly Adherence to adjuvant hormone therapy in low-income women with breast cancer: the role of provider-patient communication. Breast Cancer Res Treat, 137 (2013), pp. 829-836

[27] B. Shah, B. Chewning. Conceptualizing and measuring pharmacist-patient communication: a review of published studies. Res Social Adm Pharm, 2 (2006), pp. 153185

[28] J. Noordman, T. van der Weijden, S. van Dulmen. Effects of video-feedback on the communication, clinical competence and motivational interviewing skills of practice nurses: a pre-test posttest control group study. J Adv Nurs, 70 (2014), pp. 2272-2283

[29] A.J. Linn, J.C. van Weert, L. van Dijk, R. Horne, E.G. Smit. The value of nurses' tailored communication when discussing medicines: exploring the relationship between satisfaction, beliefs and adherence. J Health Psychol (2014) pii: 1359105314539529. [Epub ahead of print]

[30] H.S. Yin, B.P. Dreyer, H.A. Moreira, et al. Liquid medication dosing errors in children: role of provider counseling strategies. Acad Pediatr, 14 (2014), pp. 262-270 
Koster, E.S., Meeteren, M.M. van, Dijk, M. van, Bemt, B.J.F. van de, Ensing, H.T., Bouvy, M., Blom, L., Dijk, L. van. Patient-provider interaction during medication encounters: a study in outpatient pharmacies in the Netherlands. Patient Education and Counseling: $2015,98(7), 843-7$ 848

\section{TABLES}

Table 1. Characteristics of the study participants $(n=119)$.

\begin{tabular}{|l|c|}
\hline \multicolumn{1}{|c|}{} & $\%(\boldsymbol{n})$ \\
\hline \hline Male gender & $41.2(49)$ \\
\hline \hline Age $(n=70)$ & \\
\hline \hline $18-34$ & $20.0(14)$ \\
\hline \hline $35-54$ & $30.0(21)$ \\
\hline \hline $55-64$ & $18.6(13)$ \\
\hline \hline $65-74$ & $22.9(16)$ \\
\hline \hline$\geq 75$ & $8.6(6)$ \\
\hline Number of medicines per participant & \\
\hline \hline 1 & $60.5(72)$ \\
\hline \hline 2 & $23.5(28)$ \\
\hline \hline$\geq 3$ & $16.0(19)$ \\
\hline \hline Status of encounters & \\
\hline \hline First prescription encounters & $35.3(42)$ \\
\hline \hline First refill prescription encounters & $13.4(16)$ \\
\hline \hline Refill prescription encounters & $51.3(61)$ \\
\hline \hline
\end{tabular}

Table 2a. : Discussed themes of the MEDICODE during first prescription encounters in the pharmacies and the initiator of the discussion $(n=42)$.

\begin{tabular}{|l|l||l|l|}
\hline & $\begin{array}{c}\text { First } \\
\text { prescriptions } \\
\text { (\%) }\end{array}$ & $\begin{array}{l}\text { \% Pharmacy } \\
\text { technician }\end{array}$ & $\begin{array}{c}\text { \% } \\
\text { Patient }\end{array}$ \\
\hline $\begin{array}{l}\text { (1) General information about the } \\
\text { drug }\end{array}$ & & & \\
\hline \hline Medication named & $59.5(25)$ & $96.0(24)$ & $4.0(1)$ \\
\hline \hline Class named & $40.5(17)$ & $100.0(17)$ & $0.0(0)$ \\
\hline \hline $\begin{array}{l}\text { Patient asks pharmacy technician } \\
\text { questions about medication }\end{array}$ & $35.7(15)$ & $0.0(0)$ & $\begin{array}{l}100.0 \\
(15)\end{array}$ \\
\hline \hline Concerns regarding medication & $11.9(5)$ & $20.0(1)$ & $80.0(4)$ \\
\hline $\begin{array}{l}\text { Patient receives other medication } \\
\text { (e.g. other generic) }\end{array}$ & $4.8(2)$ & $0.0(0)$ & $\begin{array}{l}100.0 \\
(2)\end{array}$ \\
\hline \hline Strength of medication & $4.8(2)$ & $100.0(2)$ & $0.0(0)$ \\
\hline $\begin{array}{l}\text { Pharmacy technician asks } \\
\text { patient's opinion of medication }\end{array}$ & $0.0(0)$ & $0.0(0)$ & $0.0(0)$ \\
\hline \hline Objections regarding medication & $2.4(1)$ & $0.0(0)$ & $\begin{array}{l}100.0 \\
(1)\end{array}$ \\
\hline
\end{tabular}


Koster, E.S., Meeteren, M.M. van, Dijk, M. van, Bemt, B.J.F. van de, Ensing, H.T., Bouvy, M., Blom, L., Dijk, L. van. Patient-provider interaction during medication encounters: a study in outpatient pharmacies in the Netherlands. Patient Education and Counseling: $2015,98(7), 843-7$ 848

\begin{tabular}{|c|c|c|c|}
\hline & $\begin{array}{c}\text { First } \\
\text { prescriptions } \\
(\%) \\
\end{array}$ & $\begin{array}{l}\text { \% Pharmacy } \\
\text { technician }\end{array}$ & $\begin{array}{c}\% \\
\text { Patient }\end{array}$ \\
\hline $\begin{array}{l}\text { Doubt about effect of the } \\
\text { medication }\end{array}$ & $4.8(2)$ & $0.0(0)$ & $\begin{array}{l}100.0 \\
(2)\end{array}$ \\
\hline \multicolumn{4}{|l|}{ (2) Explanation of prescription } \\
\hline \begin{tabular}{|l} 
Instructions for medication \\
(dosage)
\end{tabular} & $95.2(40)$ & $97.5(39)$ & $2.5(1)$ \\
\hline Medication-usage issues & $83.3(35)$ & $94.3(33)$ & $5.7(2)$ \\
\hline Form of medication & $73.8(31)$ & $100.0(31)$ & $0.0(0)$ \\
\hline Reasons for taking medication & $57.1(24)$ & $91.7(22)$ & $8.3(2)$ \\
\hline Duration of treatment & $26.2(11)$ & $100.0(11)$ & $0.0(0)$ \\
\hline Costs of medication & $23.8(10)$ & $70.0(7)$ & $30.0(3)$ \\
\hline Adjustment of dosage & $19.1(8)$ & $100.0(8)$ & $0.0(0)$ \\
\hline $\begin{array}{l}\text { Conditions for not taking } \\
\text { medication }\end{array}$ & $7.1(3)$ & $100.0(3)$ & $0.0(0)$ \\
\hline $\begin{array}{l}\text { Pharmacy technician questions } \\
\text { compliance with medication } \\
\end{array}$ & $0.0(0)$ & $0.0(0)$ & $0.0(0)$ \\
\hline Compliance problems & $0.0(0)$ & $0.0(0)$ & $0.0(0)$ \\
\hline Solutions for compliance & $0.0(0)$ & $0.0(0)$ & $0.0(0)$ \\
\hline Consequences of non-compliance & $0.0(0)$ & $0.0(0)$ & $0.0(0)$ \\
\hline \multicolumn{4}{|l|}{$\begin{array}{l}\text { (3) Additional information about } \\
\text { the drug }\end{array}$} \\
\hline $\begin{array}{l}\text { Mechanism of action of } \\
\text { medication }\end{array}$ & $59.5(25)$ & $100.0(25)$ & $0.0(0)$ \\
\hline $\begin{array}{l}\text { Possible adverse effects of } \\
\text { medication }\end{array}$ & $52.4(22)$ & $95.5(21)$ & $4.5(1)$ \\
\hline \begin{tabular}{|l|} 
Expected effect on symptoms \\
\end{tabular} & $21.4(9)$ & $100.0(9)$ & $0.0(0)$ \\
\hline \begin{tabular}{|l|} 
Timeframe for expected effect \\
\end{tabular} & $21.4(9)$ & $100.0(9)$ & $0.0(0)$ \\
\hline $\begin{array}{l}\text { Pharmacy technician asks about } \\
\text { allergies/intolerance to the } \\
\text { medication }\end{array}$ & $16.7(7)$ & $100.0(7)$ & $0.0(0)$ \\
\hline Drug interactions & $9.5(4)$ & $100.0(4)$ & $0.0(0)$ \\
\hline Contraindications of medication & $7.1(3)$ & $100.0(3)$ & $0.0(0)$ \\
\hline
\end{tabular}


Koster, E.S., Meeteren, M.M. van, Dijk, M. van, Bemt, B.J.F. van de, Ensing, H.T., Bouvy, M., Blom, L., Dijk, L. van. Patient-provider interaction during medication encounters: a study in outpatient pharmacies in the Netherlands. Patient Education and Counseling: $2015,98(7), 843-7$

Table 2b. : Discussed themes of the MEDICODE during first refill prescription encounters in the pharmacies and the initiator of the discussion $(n=16)$.

\begin{tabular}{|c|c|c|c|}
\hline & $\begin{array}{c}\text { First repeat } \\
\text { prescriptions } \\
(\%) \\
\end{array}$ & \begin{tabular}{|c} 
\% Pharmacy \\
technician
\end{tabular} & $\begin{array}{c}\% \\
\text { Patient }\end{array}$ \\
\hline \multicolumn{4}{|l|}{$\begin{array}{l}\text { (1) General information about } \\
\text { the drug }\end{array}$} \\
\hline Medication named & $56.3(9)$ & $77.8(7)$ & $22.2(2)$ \\
\hline $\begin{array}{l}\text { Patient asks pharmacy } \\
\text { technician questions about } \\
\text { medication }\end{array}$ & $31.3(5)$ & $0.0(0)$ & $\mid \begin{array}{l}100.0 \\
(5)\end{array}$ \\
\hline Strength of medication & $18.8(3)$ & $100.0(3)$ & $0.0(0)$ \\
\hline Class named & $12.5(2)$ & $100.0(2)$ & $0.0(0)$ \\
\hline \begin{tabular}{|l} 
Pharmacy technician asks \\
patient's opinion of medication
\end{tabular} & $6.3(1)$ & || $100.0(1)$ & $0.0(0)$ \\
\hline $\begin{array}{l}\text { Patient receives other } \\
\text { medication (e.g. other generic) }\end{array}$ & $6.3(1)$ & $0.0(0)$ & $\begin{array}{l}100.0 \\
(1)\end{array}$ \\
\hline Concerns regarding medication & $6.3(1)$ & $0.0(0)$ & $\begin{array}{l}100.0 \\
(1)\end{array}$ \\
\hline Objections regarding medication & $0.0(0)$ & $0.0(0)$ & $0.0(0)$ \\
\hline $\begin{array}{l}\text { Doubt about effect of the } \\
\text { medication }\end{array}$ & $0.0(0)$ & $\| 0.0(0)$ & $0.0(0)$ \\
\hline \multicolumn{4}{|l|}{ (2) Explanation of prescription } \\
\hline Adjustment of dosage & $75.0(12)$ & $91.7(11)$ & $8.3(1)$ \\
\hline $\begin{array}{l}\begin{array}{l}\text { Instructions for medication } \\
\text { (dosage) }\end{array} \\
\end{array}$ & $68.8(11)$ & |100.0 (11) & $0.0(0)$ \\
\hline Form of medication & $50.0(8)$ & $87.5(7)$ & $12.5(1)$ \\
\hline Reasons for taking medication & $37.5(6)$ & $66.7(4)$ & $33.3(2)$ \\
\hline Medication-usage issues & $31.3(5)$ & $100.0(5)$ & $0.0(0)$ \\
\hline Costs of medication & $18.8(3)$ & $100.0(3)$ & $0.0(0)$ \\
\hline $\begin{array}{l}\text { Pharmacy technician questions } \\
\text { compliance with medication }\end{array}$ & $6.3(1)$ & |100.0 (1) & $0.0(0)$ \\
\hline Duration of treatment & $6.3(1)$ & $100.0(1)$ & $0.0(0)$ \\
\hline $\begin{array}{l}\text { Conditions for not taking } \\
\text { medication }\end{array}$ & $6.3(1)$ & $\mid 100.0(1)$ & $0.0(0)$ \\
\hline Compliance problems & $0.0(0)$ & $0.0(0)$ & $0.0(0)$ \\
\hline \begin{tabular}{|l|} 
Solutions for compliance \\
\end{tabular} & $0.0(0)$ & $0.0(0)$ & $0.0(0)$ \\
\hline Consequences of non- & $0.0(0)$ & $0.0(0)$ & $0.0(0)$ \\
\hline
\end{tabular}


Koster, E.S., Meeteren, M.M. van, Dijk, M. van, Bemt, B.J.F. van de, Ensing, H.T., Bouvy, M., Blom, L., Dijk, L. van. Patient-provider interaction during medication encounters: a study in outpatient pharmacies in the Netherlands. Patient Education and Counseling: 2015, 98(7), $843-7$ 848

\begin{tabular}{||l|c||c|c|}
\hline \hline & $\begin{array}{c}\text { First repeat } \\
\text { prescriptions } \\
\text { (\%) }\end{array}$ & $\begin{array}{c}\text { \% Pharmacy } \\
\text { technician }\end{array}$ & $\begin{array}{c}\text { \% } \\
\text { Patient }\end{array}$ \\
\hline \hline Compliance & & \\
\hline \hline
\end{tabular}

(3) Additional information about the drug

Pharmacy technician asks about allergies/intolerance to the medication

Mechanism of action of medication

Possible adverse effects of medication

Expected effect on symptoms

Timeframe for expected effect

\begin{tabular}{|l||l|}
\hline \hline Drug interactions \\
\hline \hline Contraindications of medication
\end{tabular}

(4) Experiences with regard to the medication

Observed adverse effects

Observed effects on symptoms

Intensity of observed adverse effects

Control of the problem

Frequency of the observed adverse effects

\begin{tabular}{|c|c|c|}
\hline $31.3(5)$ & ||100.0 (5) & $0.0(0)$ \\
\hline 18.8 (3) & ||66.7 (2) & ||33.3 (1) \\
\hline $12.5(2)$ & |50.0 (1) & $50.0(1)$ \\
\hline $6.3(1)$ & $100.0(1)$ & $0.0(0)$ \\
\hline $6.3(1)$ & $0.0(0)$ & $\begin{array}{l}100.0 \\
(1)\end{array}$ \\
\hline $0.0(0)$ & $0.0(0)$ & $0.0(0)$ \\
\hline $0.0(0)$ & $0.0(0)$ & $0.0(0)$ \\
\hline $43.8(7)$ & $85.7(6)$ & $14.3(1)$ \\
\hline $37.5(6)$ & $100.0(6)$ & $0.0(0)$ \\
\hline 18.8 (3) & $0.0(0)$ & $\begin{array}{l}100.0 \\
(3)\end{array}$ \\
\hline $12.5(2)$ & $100.0(2)$ & $0.0(0)$ \\
\hline $0.0(0)$ & $0.0(0)$ & $0.0(0)$ \\
\hline
\end{tabular}


Koster, E.S., Meeteren, M.M. van, Dijk, M. van, Bemt, B.J.F. van de, Ensing, H.T., Bouvy, M., Blom, L., Dijk, L. van. Patient-provider interaction during medication encounters: a study in outpatient pharmacies in the Netherlands. Patient Education and Counseling: $2015,98(7), 843-7$

Table 2c. : Discussed themes of the MEDICODE during refill prescription encounters in the pharmacies and the initiator of the discussion $(n=61)$.

\begin{tabular}{|c|c|c|c|}
\hline & $\begin{array}{c}\text { Repeat } \\
\text { prescriptions } \\
(\%) \\
\end{array}$ & $\begin{array}{c}\text { \% Pharmacy } \\
\text { technician }\end{array}$ & $\begin{array}{c}\% \\
\text { Patient }\end{array}$ \\
\hline \multicolumn{4}{|l|}{$\begin{array}{l}\text { (1) General information about the } \\
\text { drug }\end{array}$} \\
\hline Medication named & $70.5(43)$ & $95.4(41)$ & $4.6(2)$ \\
\hline $\begin{array}{l}\text { Patient asks pharmacy technician } \\
\text { questions about medication }\end{array}$ & $16.4(10)$ & $0.0(0)$ & $\begin{array}{l}100.0 \\
(10)\end{array}$ \\
\hline Class named & $11.5(7)$ & $85.7(6)$ & $14.3(1)$ \\
\hline $\begin{array}{l}\text { Patient receives other medication } \\
\text { (e.g. other generic) }\end{array}$ & $9.8(6)$ & $50.0(3)$ & $50.0(3)$ \\
\hline Concerns regarding medication & $6.6(4)$ & $0.0(0)$ & $\begin{array}{l}100.0 \\
(4)\end{array}$ \\
\hline Strength of medication & $3.3(2)$ & $100.0(2)$ & $0.0(0)$ \\
\hline $\begin{array}{l}\text { Doubt about effect of the } \\
\text { medication }\end{array}$ & $1.6(1)$ & $0.0(0)$ & $\begin{array}{l}100.0 \\
(1)\end{array}$ \\
\hline $\begin{array}{l}\text { Pharmacy technician asks } \\
\text { patient's opinion of medication }\end{array}$ & $0.0(0)$ & $0.0(0)$ & $0.0(0)$ \\
\hline Objections regarding medication & $0.0(0)$ & $0.0(0)$ & $0.0(0)$ \\
\hline \multicolumn{4}{|l|}{ (2) Explanation of prescription } \\
\hline $\begin{array}{l}\begin{array}{l}\text { Instructions for medication } \\
\text { (dosage) }\end{array} \\
\end{array}$ & $49.2(30)$ & $100.0(30)$ & $0.0(0)$ \\
\hline Form of medication & $42.6(26)$ & $88.5(23)$ & $11.5(3)$ \\
\hline Medication-usage issues & $27.9(17)$ & $94.1(16)$ & $5.9(1)$ \\
\hline \begin{tabular}{|l|} 
Reasons for taking medication \\
\end{tabular} & $24.6(15)$ & $53.3(8)$ & $46.7(7)$ \\
\hline Adjustment of dosage & $21.3(13)$ & $92.3(12)$ & $7.7(1)$ \\
\hline \begin{tabular}{|l|} 
Duration of treatment \\
\end{tabular} & $16.4(10)$ & $80.0(8)$ & $20.0(2)$ \\
\hline Costs of medication & $14.8(9)$ & $77.8(7)$ & $22.2(2)$ \\
\hline $\begin{array}{l}\text { Conditions for not taking } \\
\text { medication } \\
\end{array}$ & $3.3(2)$ & $50.0(1)$ & $50.0(1)$ \\
\hline $\begin{array}{l}\text { Pharmacy technician questions } \\
\text { compliance with medication }\end{array}$ & $0.0(0)$ & $0.0(0)$ & $0.0(0)$ \\
\hline Compliance problems & $0.0(0)$ & $0.0(0)$ & $0.0(0)$ \\
\hline \begin{tabular}{|l|} 
Solutions for compliance \\
\end{tabular} & $0.0(0)$ & $0.0(0)$ & $0.0(0)$ \\
\hline \begin{tabular}{|l|} 
Consequences of non-compliance \\
\end{tabular} & $0.0(0)$ & $0.0(0)$ & $0.0(0)$ \\
\hline $\begin{array}{l}\text { (3) Additional information about } \\
\text { the drug }\end{array}$ & & & \\
\hline
\end{tabular}


Koster, E.S., Meeteren, M.M. van, Dijk, M. van, Bemt, B.J.F. van de, Ensing, H.T., Bouvy, M., Blom, L., Dijk, L. van. Patient-provider interaction during medication encounters: a study in outpatient pharmacies in the Netherlands. Patient Education and Counseling: $2015,98(7), 843-7$ 848

\begin{tabular}{|c|c|c|c|}
\hline & $\begin{array}{c}\text { Repeat } \\
\text { prescriptions } \\
(\%) \\
\end{array}$ & $\begin{array}{c}\text { \% Pharmacy } \\
\text { technician }\end{array}$ & $\begin{array}{c}\% \\
\text { Patient }\end{array}$ \\
\hline $\begin{array}{l}\text { Pharmacy technician asks about } \\
\text { allergies/intolerance to the } \\
\text { medication }\end{array}$ & ||29.5 (18) & $100.0(18)$ & $0.0(0)$ \\
\hline $\begin{array}{l}\text { Possible adverse effects of } \\
\text { medication }\end{array}$ & $8.2(5)$ & || $100.0(5)$ & $0.0(0)$ \\
\hline Contraindications of medication & $3.3(2)$ & $100.0(2)$ & $0.0(0)$ \\
\hline Drug interactions & $3.3(2)$ & $50.0(1)$ & $50.0(1)$ \\
\hline Expected effect on symptoms & $3.3(2)$ & $100.0(2)$ & $0.0(0)$ \\
\hline $\begin{array}{l}\text { Mechanism of action of } \\
\text { medication }\end{array}$ & $1.6(1)$ & $\mid 100.0(1)$ & $0.0(0)$ \\
\hline Timeframe for expected effect & $0.0(0)$ & $0.0(0)$ & $0.0(0)$ \\
\hline \multicolumn{4}{|l|}{$\begin{array}{l}\text { (4) Experiences with regard to the } \\
\text { medication }\end{array}$} \\
\hline Observed adverse effects & $6.7(4)$ & $25.0(1)$ & $75.0(3)$ \\
\hline \begin{tabular}{|l} 
Observed effects on symptoms \\
\end{tabular} & $4.9(3)$ & $33.3(1)$ & $66.7(2)$ \\
\hline Control of the problem & $4.9(3)$ & $66.7(2)$ & $33.3(1)$ \\
\hline $\begin{array}{l}\text { Intensity of observed adverse } \\
\text { effects }\end{array}$ & |3.3 (2) & $50.0(1)$ & $50.0(1)$ \\
\hline $\begin{array}{l}\text { Frequency of the observed } \\
\text { adverse effects }\end{array}$ & $0.0(0)$ & $0.0(0)$ & $0.0(0)$ \\
\hline
\end{tabular}

Table 3. : Communication style of pharmacy staff during pharmaceutical encounters.

\begin{tabular}{|l||l|}
\hline & $\begin{array}{c}\text { Mean } \\
\text { (SD) }\end{array}$ \\
\hline \hline Does the pharmacy technician take the patient seriously? & \\
\hline \hline Patient is approached respectfully & $4.0(0.3)$ \\
\hline \hline Does the pharmacy technician take enough time for the patient? & \\
\hline \hline The pharmacy technician speaks calmly & $3.8(0.4)$ \\
\hline $\begin{array}{l}\text { The pharmacy technician does not interrupt the patient } \\
\text { unnecessarily }\end{array}$ & $3.9(0.4)$ \\
\hline \hline There is room for comments of the patient & $3.8(0.4)$ \\
\hline \hline Does the pharmacy technician listen attentively to the patient? & $3.0(0.4)$ \\
\hline \hline The pharmacy technician makes eye contact with the patient & $3.8(0.6)$ \\
\hline \hline $\begin{array}{l}\text { The pharmacy technician explores further questions from the } \\
\text { patient if necessary }\end{array}$
\end{tabular}


Koster, E.S., Meeteren, M.M. van, Dijk, M. van, Bemt, B.J.F. van de, Ensing, H.T., Bouvy, M., Blom, L., Dijk, L. van. Patient-provider interaction during medication encounters: a study in outpatient pharmacies in the Netherlands. Patient Education and Counseling: $2015,98(7), 843-7$ 848

\begin{tabular}{|l|c|}
\hline & $\begin{array}{c}\text { Mean } \\
\text { (SD) }\end{array}$ \\
\hline \hline The pharmacy technician responds to cues given by the patient & $3.8(0.4)$ \\
\hline
\end{tabular}

All elements scored on a 4-point Likert scale (ranging from $1=$ not at all to 4 = very much).

Table 4. Patient opinion during encounters $(n=119)$.

\begin{tabular}{||l||l|l|l|}
\hline \hline & $\begin{array}{c}\text { Prescriptions } \\
\text { \% (n) }\end{array}$ & $\begin{array}{c}\text { \% Pharmacy } \\
\text { technician (n) }\end{array}$ & $\begin{array}{c}\text { \% } \\
\text { Patient } \\
\text { (n) }\end{array}$ \\
\hline $\begin{array}{l}\text { Opinion of patient discussed } \\
\text { during encounter }\end{array}$ & $14.3(17)$ & & \\
\hline \hline Subject & & & $50.0(1)$ \\
\hline \hline $\begin{array}{l}\text { Aim/utility of the medical } \\
\text { therapy }\end{array}$ & $11.8(2)$ & $50.0(1)$ & $66.7(2)$ \\
\hline $\begin{array}{l}\text { Acceptability of adverse } \\
\text { effects }\end{array}$ & $17.6(3)$ & $33.3(1)$ & $15.4(2)$ \\
\hline \hline Existing Practical problems & $76.5(13)$ & $84.6(11)$ & $100.0(1)$ \\
\hline \hline Intends to start using & $5.9(1)$ & $0.0(0)$ & \\
\hline
\end{tabular}

